\title{
Among Followers and Rebels: Professional Identity and Digitalization of Work
}

\author{
Karin Högberg \\ University West \\ Karin.hogberg@hy.se
}

\author{
Sara Willermark \\ University West \\ Sara.willermark@hv.se
}

\begin{abstract}
The digitalization of work practices has changed many professions. In this study, we explore the relation between professional identity and digitalization in the workplace. We join the research stream within professional identity research that views identity as a narrative construction, a story that individuals tell themselves and others to tell who they are, in this case in relation to digitalization. The empirical data derive from two different contexts: Nordic primary school teachers and European hoteliers at an international hotel chain. In total, 72 interviews were conducted. The study contributes to existing literature by providing increased knowledge on digitalization of work practices by illustrating different approaches to digitalization of work that extend over a specific profession. Theoretical contributions involve presenting a new model highlight the intricate interplay between technology and professional identity and how it creates different positions and approaches in a digitalized working life. Practical contribution includes implications for management. Key words: digitalization, professional identity, digital frames, cross-case study
\end{abstract}

\section{Introduction}

The digitalization of society has increasingly affected a range of industries, such as healthcare, education and tourism, to mention a few [1-3]. Two decades ago, IT such as emails and teleconference systems represented new ways for organizations to communicate internally and externally [4]. Currently, the growth of digital technologies continues to impact organizations in new ways [4] and transform organizational routines, processes and, not least, work tasks and professional roles [5]. Researchers discuss that digitalization of organizations today is less about technology and more about strategy and that "less digitally mature organizations tend to focus on individual technologies and have strategies that are decidedly operational in focus" [5, p. 3]. Thus, while early digitalization initiatives were regarded as "IT projects" or "IT strategies," it is no longer possible to make a clear distinction between organizational strategy and IS strategy [6-8], and digital strategies in the most mature organizations are developed with an eye on develop the organization, rather than the technology per se. The digitalization of organizations can be seen from a "fusion view," that is, instead of viewing the implementation of IT as projects, it can be viewed as a transformation and strategy where the organization and technology are equally central [9]. In the present paper, we consider digitalization of workplaces as a transformation that disrupts and changes organizational processes, routines and work tasks. Consequently, this means transforming workplaces, professional activities and interactions and thus challenging professional identity. However, we still know little about organizational change and changes in work tasks induced by the introduction of digital processes [5] and the changed conditions for different professions [10] which often bring increased complexity to work [11]. Despite the ubiquitous presence of IT in workplace contexts there is still little research that investigates the relationship between professional identity and IT use [1, 12]. Professional identity refers to an individual's image of who they are as a professional and concerns attitudes, values and motives related to the profession and its work tasks [13]. Earlier IS research has taken a slightly fragmented perspective on professional identity and IT [12]. A more nuanced understanding of the disruptive force of the digitalization of workplaces and its relationship to identity dynamics is therefore necessary $[10,14]$. The present study aims to fill some of this gap by studying the relation between professional identity and digitalization in the workplace. More specifically, we examine the relationship between existing professional identity and the digitalization process. By examining professional identity in relation to digitalization of work, we can better understand how it is received by 
organization members and its consequences for work practices. The research question is as follows: How can the relationship between digitalization of workplaces and professional identities be understood?

\section{Research context}

In this study, we explore professional identity and the digitalization of work within the domains of school and primary school teachers as well as a hotel chain and hotel employees (referred to as "hoteliers"). In the case of schools, digitalization has been on the political agenda for quite some time and various stakeholders such as policy makers, educators, technology producers, and society at large express different hopes and expectations concerning what such transformation can lead to. The digitalization of school affects administration and communication as well as the activities that are carried out in the classroom. However, integrating technology in teaching has proven to be a complex process $[15,16]$. There is research that points to the advantages as well as disadvantages when technology is introduced in teaching practice, and many teachers feel unprepared to use technology in teaching $[17$, 18]. In the case of the hospitality industry, digitalization is mainly a driver for increased competiveness and a way of providing more value to customers [2]. Also, the advance of digital platforms such as Booking.com and Hotels.com has transformed and disrupted the industry [2]. Today, many hotel guests book their room on these platforms, which creates new routines for the hotels, which are no longer in charge of the hotel guests' entire journey. Similarly, digital platforms have created new arenas for service encounters, which in practice means that the hotels need to provide service both in physical as well as digital arenas [19].

\section{Related Research and Theoretical Framing}

This section deals with theory and related work of professional identity, especially related to IT. In the past decade interest in professional identity has grown [12]. In the present paper, we draw on research that conceptualizes identity and focuses on questions like, "Who am I?" or "How to act?" in relation to professional work and social categories [20]. These concepts help us understand how people construct and present multiple identities throughout life, including their professional identities. The process of identity development can best be characterized as an ongoing process, a process of interpreting oneself as a certain kind of person and professional and being recognized as such in a given context [21]. Professional identity refers not only to the impact of the expectations of other people, for example, social constructions in society about what a teacher should know and do, but also to what teachers themselves find central in their professional work and lives based on both their experiences in practice and their individual backgrounds [22]. Professional identify has been studied in organizational, social/group and individual levels of analysis. The concept of identity is widely studied in many research contexts, for example, personal identity (cf.[23]), professional identity on an individual level (cf.[13]), social identity focusing on groups [24] and organizational identity (cf. [25]). At the individual level, earlier studies have emphasized the need to explain how the networks of different roles and relationships that individuals are set in affect their role and behavior [26]. Research on the individual level has also focused on explaining how the networks of roles and relationships that individuals have in different contexts affect their identity and, consequently, their behavior [26]. At the group level, researchers have focused on the question "Who are we?" at the group, organizational, or societal level [24, 27] and how identity is derived from membership in social groups and how group membership motivates individuals to become like others in the group. At an organizational level, research has emphasized that identity exists in interpretive schemes that organizational members jointly construct to provide meaning to their history, and activities [28]. Through constant interactions, organizational members negotiate questions like "who are we as an organization" [29, 30].

In the past decade IT has become an essential part of how individuals understand themselves and act in our digital society [31]. Research on professional identity and technology spans over several research fields. While organizational researchers have focused on professional identity and organizational identity, research on information systems has put a large emphasis on professional identity through the use of IT, often referred to as IT identity [32]. However, although there is an increasing interest in issues concerning professional identity and IT, there is a lack of in-depth empirical studies that analyzes the relationship between the process of professional identity and digitalization of work [10]. Increasingly, IT and how it transforms professional activities is widely studied by the IS research field [33]. Yet the relation between identity and material object, such as 
IT, is less studied [20]. The drivers and barriers to successful implementation of information systems have long been of interest to researchers [34] and how identity may be involved in this process has been explored in a number of studies. For example, a wide stream of IS research has studied how individual identity is indirectly affected by IT, for example, by changing work practices and professional roles [10]. These studies have focused on a variety of IT artefacts and contexts. For example, Gal et al. [35] studied how threedimensional technologies were implemented in the architecture industry. Similarly, Alvarez [36] also highlighted the co-construction of identity and information systems and discussed how technology, structure and identity are jointly constitutive. Korica and Molloy [37] investigated identity from a process perspective by illustrating how medical professionals understand the relationship between new technology and their professional identities and found the role of changing insider and outsider dynamics to be relevant when recognizing professional identity as in constant flux at micro, meta and macro levels. Another stream of research has focused on how IT implementation and use in workplace contexts has changed and disrupted existing professional activities. Studies have for example tried to explain how IT challenges traditional assumptions about professional identity [19]. Thus, IS researchers have primarily focused on how IT shapes professional identities [38]. For example, Walsham [38] investigated how bank managers' professional identity changed after the implementation of a decision-support system. Similarly, Lamb and Davidson [39] studied how the professional identity among research scientists in oceanography and marine biology was shaped by the use of IT. Davis and Hufnagel [39] revealed the effects of an automation system on the work roles of fingerprint technicians. More recently, IS researchers have generally studied identity in the context of online communities [34]. By using a pathological perspective, Polites et al. [34] investigated the role of identity in relation to an individual's perceptions of his or her social media use. The study develops the concept of IT identity, i.e., the extent to which an individual perceives an IT as central to one's identity. Kim et al. [40] examined what motivates individuals that take part in online communities to buy digital items and found that a decision to buy such items is driven by the individual's wish for online selfpresentation. Da Cunha and Orlikowski [41] examined how employees used an online forum to help them deal with identity threats. Another stream of research has studied how IT functions as a referent for individuals, that is, how IT has a direct impact on individual identity. To summarize: the present article is in the stream of research that views identify as a process, hence the longitudinal research design of the study. We use identity theory as a construct to investigate the interplay between individual professional identity and digitalization of work. Unlike the large stream of research focusing on collective and organizational identity (cf. [27, 42]), the present study focuses on individual employees' professional identity. If established meaning linkages between professional identity and individuals' work practices changes, in this case due to rapid digitalization, it can promptly change the individual's professional identity. On the other hand, the professional identity also affects the interpretations of the new work practices (here digitalization). Consequently, we view the study of professional identity as an interplay of identity construction and the digitalization process. Furthermore, to illustrate the process, we join the research stream within professional identity research that views identity work as a narrative. That is, identity is seen as a narrative construction, a story that individuals tell themselves and others which is developed over time [43]. As individuals, we continually construct and develop identity narratives by combining our own experience of our self with reactions from family, organizational members and society at large. In other words, we develop and refine our professional identity through self-reflection and in interaction with others [44]. Professional identity narratives contain both aspects wherein the individuals state their own identity as a professional and part of the institution (i.e., professional organization, etc.) and also express membership in a particular professional role [45]. Giddens [46] discusses identity as knowledge, emotions, abilities, and experiences that are organized around a social role, with professional identity referring to those elements organized around a particular occupational role. Professional identity can therefore be seen as a particular type of narrative that develops over time in interaction with external actors such as employers and other industry representatives, but also internal factors such as development of the individual's understanding of the profession and how to practice it [45]. Barrett and Walsham [47] developed Giddens' work by theoretically linking the macro-level and micro-level entanglement of ITs for professional identity. They discuss that the introduction of new ITs in the workplace has an important impact on the structuring of professional expertise and that the introduction of IT can create concerns about professionals' knowledge and work skills. Hence, traditional work 
roles and skills are challenged by IT, as is professional identity.

\section{Method}

In order to explore professional identity in relation to digitalization we have chosen a cross-case study methodology with a qualitative approach [48].This approach was adopted for two main reasons. First, it enables investigation of a contemporary phenomenon within its natural setting [48]. Since the main objective of this study was to develop a rich, theoretical understanding, an exploratory approach, which enables predicting similar results, seemed particularly useful. The following criteria were used to select cases: a) the cases would cover both public and private organizations; hence the choice of schools and hotels b) the digitalization of work should be multifaceted in its nature, which means that it affects the organization on several levels and that the work cannot be fully regulated; and c) key stakeholders (employees) were available for interviews and observations. Secondly, it facilitated an exploration of professional identity and digitalization of work within different contexts. Thus, whenever there are two cases, a cross-case analysis of the findings is likely to be more robust in confirming, challenging or extending existing theory and knowledge [48]

\subsection{Data}

The data was generated mainly from individual, semi-structured, in-depth interviews with primary school teachers and hotel employees (hereafter referred to as "employees" if no distinction between the different professions is necessary). This was to get the employees' perspective of technology within their work. A total of 72 interviews were conducted, of which 35 with teachers (including 14 follow-up interviews) and 37 with hotel employees (including 15 follow up interviews). (See Table 1). The interviews had an explorative approach towards the views of employees' reflections upon and actual use of technology. The researchers followed a semistructured interview procedure to ask questions about how they made sense of technology in the workplace. We chose individual interviews, since we were interested in each employee's perception of their own work practice, their professional identity and experiences. An interview protocol was developed to elicit information and the interviews were organized in three themes to explore how they make sense of the new technology: 1) Professional identity (including work tasks and work situation) which included questions such as: "Why did you become a teacher/hotel employee?", "What role does your work play in your life?" and "What constitutes your main work tasks?"; 2) Perception of technology involving overall view of technology and technological interest (or lack of it) which included questions such as: "What is your approach to technology?" and "How does technology affect your everyday life?"; 3) Digitalization of the profession which involves how the changed professional role is viewed and how this is addressed in the employee's work. It involves questions such as: "Can you describe how your organization use technology?", "How do you use technology in your work", "What do you believe to be the advantages of using technology?" and "What do you believe to be the disadvantages of using technology?" Each theme had an explicit purpose and a set of open-ended questions for the interviewer to choose from, all with the intention to get the respondents in a narrative frame of mind to describe and give examples based on their own experiences. The narration-based inquiry approach was intended to not only describe actual situations but also uncover the respondent's experiences and perceptions of the topics of interest. Follow-up interviews were conducted regularly, to examine the individual employee's interpretation and usage of technology over time. The interview questions were developed based on the previous interviews and continuous observations of the employees' activities. The followup interviews were based on availability. Ethical guidelines were followed and informed consent was obtained from all participants. The duration of the interviews ranged from 30 to $80 \mathrm{~min}$. The interviews were electronically recorded and transcribed. The interviews were conducted between 2013-2017. Additionally, complementary data included observations of the employees' work context. This involved teachers' planning meetings, classroom teaching and reflection sessions from school as well as online observation on social media platforms from the hotel organization. Written documentation of teaching and learning material from school and social media strategies and guidelines from the hotel was also collected, to get a more holistic understanding of the work context and technology usage. Thus, the complementary data was used to ask more informed interview questions, and enable a more initiated analysis where the respondents' narratives could be linked to external observations, and thus it provided the opportunity to ask questions such as, "I noticed that X, why is that?" The interviews provide evidence about the professional identity and digitalization. An 
estimation of observed time is 120 hours for teachers and 60 hours for hotel employees.

\begin{tabular}{|l|l|l|}
\hline Data & Teachers & Hotel employees \\
\hline Interviews & $\begin{array}{l}\text { 35 interviews of } \\
\text { which 14 were } \\
\text { follow-up } \\
\text { interviews }\end{array}$ & $\begin{array}{l}37 \text { interviews } \\
\text { with hotel } \\
\text { employees of } \\
\text { which 15 follow- } \\
\text { up interviews }\end{array}$ \\
\hline Observations & $\begin{array}{l}\text { E.g. teaching } \\
\text { activities and } \\
\text { classroom } \\
\text { teaching and } \\
\text { reflection } \\
\text { sessions. }\end{array}$ & $\begin{array}{l}\text { Hotel } \\
\text { organizations and } \\
\text { netnography of } \\
\text { social media } \\
\text { platforms. }\end{array}$ \\
\hline Other data & $\begin{array}{l}\text { Documentation } \\
\text { of teaching and } \\
\text { learning } \\
\text { material, e.g. } \\
\text { planning } \\
\text { documents, }\end{array}$ & $\begin{array}{l}\text { Written } \\
\text { documents of } \\
\text { social media } \\
\text { strategies and } \\
\text { guidelines were } \\
\text { collected }\end{array}$ \\
\hline
\end{tabular}

Table 1. Overview of empirical data

\subsection{Analysis}

The interviews were analyzed based on a narrative interpretive approach where the respondents' stories are given a voice. Narrative analysis was used to identify specific themes within the transcriptions. The data was analyzed by a spiral procedure focusing on the meanings of the parts and then linking them with the whole in an integrative manner. In doing so, an understanding of the studied phenomena could be achieved. The first step was to read the transcripts repeatedly and create a holistic understanding of the employees' stories. By going back and forth through the data, a sensemaking of the data was created, using open coding processes with fictive names of respondents. Each individual interview transcript was examined using the same analytical processes, where the complementary data sources were used in order to create more holistic understanding of the technology use and the respondents' professional identity and perception of technology, but also following the development of the professional identity narrative over time [45]. During the analysis we discovered patterns of similarities and differences of how the respondents' perception and behaviour linked to the digitalization of their work and decided to apply ideal types of categorization to tell the employees' stories. One quote from a hotel employee illustrates this: "I have worked with service for 20 years, it is what I love, and I am not sure that all technology makes me better". The interpretive paradigm used here assumes that language represents interpretations within a context of shared social practice. Here we could identify differences between teachers and hotel employees regarding their professional identity. For hoteliers, it is mainly rooted in practical experience of providing service, while teachers professional identity is closely tied to experiences as well as education, and they emphasize that they are academics. However, this aside we were able to identify the same type of pattern among teachers and hoteliers based on their degree of professional identity and technological interest. Based on these finding we constructed four ideal type narratives. To cover the widest possible range of different views, extreme positions were chosen as the basis for the first analysis and then intermediate positions between these extremes were added and thus fuller and more nuanced portraits were formed gradually.

\section{Results and Analysis}

Below, we present and discuss the patterns identified between technological perception and how it forms patterns of different approaches to the digitalization of the profession. The degree of technical knowledge and the degree of professional identity form different positions. The professional identity can either be threatened by or benefit from the digitalization, and employees assume different approaches to meet (or avoid meeting) requirements for digitalization. These categories are as follows: the enthusiast, the rebel, the follower and the unconcerned. The respective category is described more in-depth below, and each category is illustrated with two examples, one from teachers and one from hotel employees. However, before we describe these categories, we illustrate the anchors of the respondents' professional identities and their understanding of the digitalization of work.

\subsection{The Anchors of Professional Identity'}

The symbols of professional identity are gained through a number of social processes-formal education and training, organizational membership, status and seniority in one's profession $[13,20]$. From the respondents' narrative self-descriptions, we noted that the teachers, in contrast to the hoteliers, often described identity through their education and experience. However, similarities in the narratives of professional identities were noted as many teachers as well as s described their work as a way of "being" 
[13]. For example, teachers expressed that they "love to see their students grow" and the hoteliers expressed that they "love service".

\subsection{Categorizations of Professional Identities and Technology}

The following discussion presents the four categorizations of professional identity in our analysis of the data. These are illustrated with the most striking examples from the transcript and demonstrate the intertwinement of professional identity and digitalization of work. The degree of professional identity and technological knowledge respectively builds different approaches to the changed professional role, where it can promote or threaten one's professional identity.

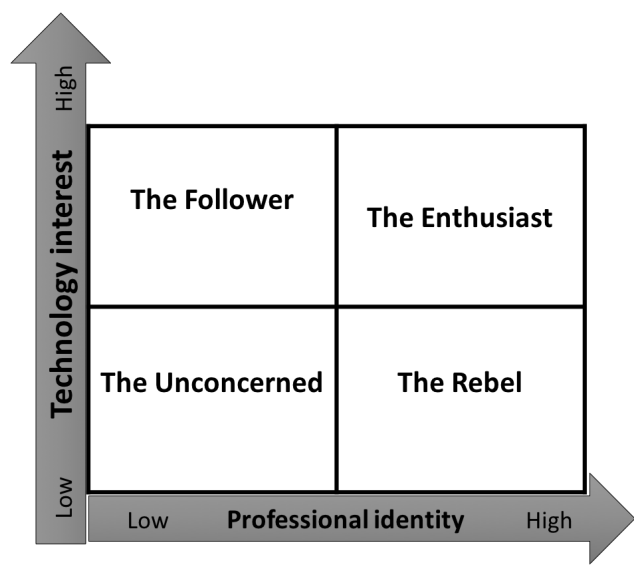

Figure 1. Ideal type categorization based on degree of professional identity and technological interest

\subsection{The Enthusiast}

Narratives from respondents categorized as "The Enthusiast" express that they are experiencing opportunities related to digitalization of the profession and expressing hopes and expectations related to the transformation. Hence, the professional identity is perceived as strengthened by a digitalization [13].

5.3.1 Ann, Teacher; has worked as a teacher for five years. Even though she is relatively new as a teacher she relates strongly to the profession. Her mother worked as a teacher and made a career in education and she describes that education was a frequently discussed topic during her upbringing. Ann is interested in digital technology and sees many advantages in technology use, both privately and at work. Yet, she states that she is not a "technological geek" or a "technical genius." Ann considers the digitalization of school as a matter of course, as illustrated by: "To imagine a school without technology is very strange... the school must reflect the society we live in, right?" She has been commissioned to support the digitalization at her school, by being responsible for local professional development among colleagues. Thus, she has been given a key role in the school through her assignment, although she is relatively new as a teacher.

5.3.2 Tim, hotelier; describes a similar attitude towards digitalization. Tim has worked in different positions at various hotels for the past 15 years. He started out in reception and has "worked his way up." A couple of years ago, his employer encouraged him to take courses at the university. This led to him getting a new position at the hotel as head of customer relationships. These courses together with his interest in technology have strengthened his professional identity and given him greater confidence in his professional role. He describes that he is a "social media junkie" and views his iPhone as his most important work tools and "always have it in my hand." Due to the hotel's large investment in digitalization and social media, his professional role has become vital.

\subsection{The Rebel}

As the name suggests, the rebel resists the digitalization of the profession and rebels against the pressures encountered, and the professional identity is perceived as threatened by digitalization. Furthermore, the narratives of the "rebels" reveal a "disidentification" [49] related to digitalization.

5.4.1 Ewa, teacher; has worked as a primary school teacher for 33 years, that is, almost all her adult life. She holds a strong professional identity. She not only works as a teacher, she is a teacher. Ewa reports a low degree of interest in technology and technology use in her everyday life. Instead, she describes the satisfaction of opening a print magazine and hearing it rustle. She questions the digitalization of the school, based on her own will and conviction, as illustrated by: "Computers are not my tool, nor should it be the students' tools...." She argues that the students learn when they shape letters by hand, and that the digital work method inhibits their experience. The school's digitalization, makes her uncertain and alien to her work, and as if time has run past her. She resists changing her professional practice as a consequence of digitalization. She can't find the arguments for digitizing the teaching, and thus she 
resists. Instead, she assigns this work to other colleagues or to the students themselves, as illustrated by: "I have some colleagues who are very good at technology and they run... and the students themselves are knowledgeable on this, they know a lot."

5.4.2 Robin, hotelier; has been working in hospitality for 15 years and has worked in reception and is now in charge of customer relationships, which involves managing the reception but also providing service online and being in charge of booking. He is skeptical about digitalization and argues that it does not give more value to the customer, but does produce more administrative work for him and his team and changes existing organizational routines. "I mean sure, a guest can ask a question on Twitter, but what is the value of that if we are not there to answer it?" Most of all he interprets that the hotel management and their devotion and optimism in digitalization is provocative. His narrative illustrates that he believes that digitalization is a way of controlling him and the other employees. "I mean soon they will start to ask for statistics, how many this and how many that. What is the point of that, how does it make us better at giving good service?"

\subsection{The Follower}

The follower adapts to the digitalization and incorporates it into their profession. The digitalization of the work is seen as an undramatic and natural part of society's digitalization, which can mean both a renewal and extra work effort.

5.5.1 Dan, teacher; has worked as a teacher for a long time and has experiences from different stages and within various subjects. He will soon be retired and have more time for his interests. He has no strong professional identity, he describe being a teacher as a job, sometimes a fun and stimulating job, but it does not define him. He acknowledges that there are advantages to the teaching profession, but the development towards more administration and heavy workload made him lose interest at work. He has a newfound interest in technology and highlights that the digitalization gave him new inspiration, as illustrated by: One year ago, I thought that I might have to do something else.... Because of the workload. But then I signed up for a course online and I became more interested in computers. So it became a motivation to keep going.

5.5.2 Tina, hotelier; has worked in the hospitality industry for 18 years and has had different positions. She is currently working as manager of reception and booking. Hence she has experienced many, rather disruptive transformations, e.g. of how guests book rooms and how to provide service. Her work tasks includes answering questions and reviews from hotel guests in social media. Her narratives describe that her professional identity is rather weak, and she does not see digitalization as a threat or concern. She describes herself as "quite normal" when it comes to interest in technology and says that she "looks at Facebook and Instagram." Also, she is not critical about the changes and is positive about strategic decisions made by the hotel management, but sees them as a natural part of surviving in the hotel industry.

\subsection{The Unconcerned}

The unconcerned lack interest in the digitalization of work and do not worry about the transformation. Professional identity as well as interest in digitalization is weak, and the digitalization of work is not perceived as either a threat or an opportunity.

5.6.1 Catarina, teacher; has been working as a teacher for 13 years. She recently returned to the teaching profession after working in a bookstore for a few years. She describes that the high workload drove her away from the teaching profession, and the fact that she was unable to do the work she wanted to. However, the uncomfortable working hours in the bookstore combined with family life made her go back. Unlike the last time she was working as a teacher, she stresses the importance of limiting her commitment and does not let the job be more than just a job, She has a rather weak technical interest and is not a frequent technology user. She mainly uses technology in planning her teaching, to browse the internet to get tips on how to plan lessons, as illustrated by: "It's a way for me to save time, I love saving time... why should you reinvent the wheel?" Yet, technology does not have a central role in her teaching, as she argues that it would take a lot of time and dedication. She does not rebel against digitalization or see it as threatening, but neither engage in the process.

5.6.2 Sandra, hotelier; has been working in the hotel industry for five years. She is manager of customer relationships, which involves managing reception and booking and has responsibility for the hotel's social media channels. She is uninterested in technology and is frank about the fact that she doesn't always understand the usefulness of it. She has a weak professional identity and she expresses that she is not certain that she will work in the hospitality industry 
for her entire career. When it comes to service she appreciates the physical meetings and believes that it is easier to provide service in the physical reception than in digital platforms. The narratives illustrate that Sandra's way of coping with the changes made by digitalization is to avoid them as much as possible. She says: "Yes, we are supposed to use Twitter, but I don't really understand how it works so I use Facebook instead, I know how that works.",

\section{Discussion}

In the present paper, the interplay between the individual's professional identity and digital technology in the workplace has been studied. We theorized above that professional identity is related to the digitalization process. That is, we emphasize that the individual respondents construct, and reconstruct, their professional identities in relation to their understanding of the digitalization of work and the work practices related to it. The analysis suggests four types of professional identity categories to describe and understand the co-relationship between existing professional identity and the digitalization of work. The narratives support existing insights on the interplay between professional identity and technology. For example, resistance to adoption of new technology and how professional groups alternately make sense of the same technology, in relation to the same work tasks. Furthermore, the narratives are congruent with established insights from earlier studies of technology that show tensions and contradictions between professional groups due to the implementation of new technology. However, the narratives also draw attention to the relationship between professional identity and digitalization of workplaces, which is relatively underdeveloped and understudied in the literature $[10,12]$. In our analysis, we found a relationship between professional identity and technology interest, including the interpretations of the digitalization process and professional identity (see Figure 1). By categorizing our findings into four categories of professional identity, we have provided a basis for examining the co-creation of professional identity and the digitalization of work. Hence, we have moved beyond taking a unilateral perspective, e.g., focusing merely on how professional identity affects technology use or vice versa, and hence we also make a theoretical contribution to existing literature. The "Enthusiast" category consists of respondents that express that the process of digitizing work seems to be identity enhancing (cf. [50], because they enable the respondents to do what they themselves believe to be a better job. Hence, the "Enthusiast" has a high degree of both technology interest and professional identity. The "Rebel" on the other hand has a high level of professional identity but lacks interest in the digitalization process. Hence narratives in this categorization express a resistance towards the changes deriving from the technology use. The narratives are closely related to selfpresentation, that is, "this is who I am" [13] and disidentification with technology [50], and colleagues that are positive towards it are perceived to strengthen the professional identity. This category also presented a high degree of resistance towards the change caused by digitalization. An opposite approach was found in the category of the "Follower," whose narratives illustrate respondents with a low degree of professional identity that easily adapt to change and are positive towards the digitalization process. Finally, the category of the "Unconcerned" illustrates respondents with weak professional identity as well as low interest in the digitalization process.

\section{Conclusion}

We have shown different approaches to digitalization of work, which captures the individual employees' view of the digitalization of professional identity as well as their actions in their professional role. Our findings contribute to the understanding of the relationship between digitalization of work and professional identity in the IS research field. Theoretical contribution includes moving beyond taking a unilateral perspective, e.g., focusing merely on how professional identity affects technology use or vice versa and have demonstrated the relationship between professional identity and technology that extends across a specific profession. Furthermore, we shed light on the intricate interplay between technology and professional identity and how it creates different positions and approaches in a digitalized working life. Practical implications include a practice-rooted model that can be useful for management to identify, understand and evaluate the process of digitalization in their own organization.

\section{References}

[1] M.-K. Stein, R. D. Galliers, and M. L. Markus, "Towards an understanding of identity and technology in the workplace," Journal of Information Technology, vol. 28, pp. 167-182, 2013.

[2] M. Sigala, "Collaborative commerce in tourism: implications for research and 
industry," Current Issues in Tourism, vol. 20, pp. 346-355, 2017.

[3] S. Aral, C. Dellarocas, and D. Godes, "Introduction to the special issue-social media and business transformation: a framework for research," Information Systems Research, vol. 24, pp. 3-13, 2013.

[4] X. N. Deng, E. Gonzalez, and T. D. Wang, "Introduction to the Minitrack on Digital and Social Media in Enterprise," in Proceedings of the 52nd Hawaii International Conference on System Sciences, 2019.

[5] R. Kumar, "Future of profession," Journal of family medicine and primary care, vol. 5, p. 745, 2016.

[6] R. D. Galliers, "Further developments in information systems strategizing: unpacking the concept," The Oxford Handbook of Information Systems: Critical Perspectives and New Directions. Oxford University Press, Oxford, pp. 329-345, 2011.

[7] S. Mithas, A. Tafti, and W. Mitchell, "How a firm's competitive environment and digital strategic posture influence digital business strategy," MIS quarterly, pp. 511-536, 2013.

[8] A. Bharadwaj, O. A. El Sawy, P. A. Pavlou, and N. Venkatraman, "Digital business strategy: toward a next generation of insights," MIS Quarterly, pp. 471-482, 2013.

[9] J. W. Ross, C. M. Beath, and I. M. Sebastian, "How to develop a great digital strategy," MIT Sloan Management Review, vol. 58, p. 7, 2017.

[10] J. D. Boudreau, M. E. Macdonald, and Y. Steinert, "Affirming professional identities through an apprenticeship: insights from a four-year longitudinal case study," Academic Medicine, vol. 89, pp. 1038-1045, 2014.

[11] M. Koehler and P. Mishra, "What Is Technological Pedagogical Content Knowledge?," Contemporary Issues in Technology and Teacher Education (CITE Journal), vol. 9, pp. 60-70, 2009.

[12] E. Jussupow, K. Spohrer, A. Heinzl, and C. Link, "I am; We are-Conceptualizing Professional Identity Threats from Information Technology," 2018.

[13] H. Ibarra, "Provisional selves: Experimenting with image and identity in professional adaptation," Administrative Science Quarterly, vol. 44, pp. 764-791, 1999.
[14] K. Lyytinen and M. Newman, "Explaining information systems change: a punctuated socio-technical change model," European Journal of Information Systems, vol. 17, pp. 589-613, 2008.

[15] S. Willermark and L. Pareto, "Challenges of Achieving ICT Competent Teachers through Continuing Professional Development: Teachers' perspectives," IRIS Selected Papers of the Information Systems Research Seminar in Scandinavia, pp. 103-117, 2013.

[16] S. Willermark, "Digital Didaktisk Design: Att utveckla undervisning $i$ och för en digitaliserad skola," Högskolan Väst, 2018.

[17] A. Hutchison and D. Reinking, "Teachers' perceptions of integrating information and communication technologies into literacy instruction: A national survey in the United States," Reading Research Quarterly, vol. 46, pp. 312-333, 2011.

[18] Skolverket, "IT-användning och ITkompetens i skolan. Skolverkets ITuppföljning 2015

[19] K. Högberg, "Persistent Digital Service Encounters: Challenges of organizational use of social media in a hotel chain," University West, 2018.

[20] V. L. Vignoles, S. J. Schwartz, and K. Luyckx, "Introduction: Toward an integrative view of identity," in Handbook of identity theory and research, ed: Springer, 2011, pp. 1-27.

[21] J. P. Gee, "Education identity as an analytic lens for research," Rev. Res. Educ, vol. 25, pp. 99-125, 2001.

[22] L. Tickle, Teacher induction: The way ahead: Open University Press Buckingham, 2000.

[23] H. W. Noonan, Personal identity: Routledge, 2019.

[24] H. Tajfel, Human groups and social categories: Studies in social psychology: CUP Archive, 1981.

[25] M. J. Hatch and M. Schultz, "Scaling the tower of Babel: Relational Differences Between Identity, Land Culture in Organizations," in The expressive organization: Linking identity, reputation, and the corporate brand, ed: Oxford University Press, 2000, pp. 11-35.

[26] P. J. Burke and J. E. Stets, Identity theory: Oxford University Press, 2009.

[27] B. E. Ashforth, S. H. Harrison, and K. G. Corley, "Identification in organizations: An examination of four fundamental questions," 
Journal of management, vol. 34, pp. 325374, 2008.

[28] D. Ravasi and M. Schultz, "Responding to organizational identity threats: Exploring the role of organizational culture," Academy of management journal, vol. 49, pp. 433-458, 2006.

[29] S. Albert and D. A. Whetten, "Organizational identity: Research in organizational behavior," Greenwich, CT, 1985.

[30] M. G. Pratt, K. W. Rockmann, and J. B. Kaufmann, "Constructing professional identity: The role of work and identity learning cycles in the customization of identity among medical residents," Academy of Management Journal, vol. 49, pp. 235262, 2006.

[31] M. Carter, "Me, my self, and I (T): conceptualizing information technology identity and its implications," MIS Quarterly, vol. 39, 2015.

[32] U. Schultze and W. J. Orlikowski, "Research commentary_-Virtual worlds: A performative perspective on globally distributed, immersive work," Information Systems Research, vol. 21, pp. 810-821, 2010.

[33] S. Zuboff, In the age of the smart machine: The future of work and power vol. 186: Basic Books New York, 1988.

[34] M. A. Whitley and D. S. Walsh, "A framework for the design and implementation of service-learning courses," Journal of Physical Education, Recreation and Dance, vol. 85, pp. 34-39, 2014.

[35] U. Gal, K. Lyytinen, and Y. Yoo, "The dynamics of IT boundary objects, information infrastructures, and organisational identities: the introduction of 3D modelling technologies into the architecture, engineering, and construction industry," European journal of information systems, vol. 17, pp. 290-304, 2008.

[36] R. Alvarez, "Examining technology, structure and identity during an enterprise system implementation," Information Systems Journal, vol. 18, pp. 203-224, 2008.

[37] M. Korica and E. Molloy, "Making sense of professional identities: Stories of medical professionals and new technologies," Human relations, vol. 63, pp. 1879-1901, 2010.
[38] G. Walsham, "Cross-cultural software production and use: a structurational analysis," MIS quarterly, pp. 359-380, 2002.

[39] C. Davis and E. M. Hufnagel, "Through the eyes of experts: A socio-cognitive perspective on the automation of fingerprint work," 2007.

[40] H.-W. Kim, H. C. Chan, and A. Kankanhalli, "What motivates people to purchase digital items on virtual community websites? The desire for online selfpresentation," Information systems research, vol. 23, pp. 1232-1245, 2012.

[41] J. V. Da Cunha and W. J. Orlikowski, "Performing catharsis: The use of online discussion forums in organizational change," Information and Organization, vol. 18, pp. 132-156, 2008.

[42] J. E. Stets and P. J. Burke, "Identity theory and social identity theory," Social psychology quarterly, pp. 224-237, 2000.

[43] D. P. McAdams, "Identity and the life story," Autobiographical memory and the construction of a narrative self: Developmental and cultural perspectives, vol. 9, pp. 187-207, 2003.

[44] M. Eliot and J. Turns, "Constructing professional portfolios: Sense-making and professional identity development for engineering undergraduates," Journal of Engineering Education, vol. 100, pp. 630654, 2011.

[45] C. Chamberlin, "It's not brain surgery": Construction of professional identity through personal narrative," Teaching and learning, vol. 16, pp. 69-79, 2002.

[46] A. Giddens, Modernity and self-identity: Self and society in the late modern age: Stanford university press, 1991.

[47] M. Barrett and G. Walsham, "Electronic trading and work transformation in the London insurance market," Information Systems Research, vol. 10, pp. 1-22, 1999.

[48] K. Yin Robert, "Case study research: design and methods," sage publications, 1994.

[49] S. Sveningsson and M. Alvesson, "Managing managerial identities: Organizational fragmentation, discourse and identity struggle," Human relations, vol. 56, pp. 1163-1193, 2003.

[50] R. Lamb and E. Davidson, "Information and communication technology challenges to scientific professional identity," The Information Society, vol. 21, pp. 1-24, 2005. 